\title{
Comentarios al Informe rendido por el Profesor Ramírez Merchan sobre el trabajo del Dr. Isaías Arenas Buenahora
}

(Sesión del 8 de octubre de 1953)

Dr. SILVA.-De forceps alto sólo debe tratarse entre especialistas y jamás mencionarlo en la enseñanza universitaria. Como bien dice el Profesor Ramírez, la aplicación del forceps por encima del estrecho superior es a veces factible y de buenos resultados, pero personalmente soy adverso a la práctica de estas aplicaciones de forceps.

Dr. CUBILlOS. - Sería de desear que el Profesor Ramírez aclarase si cuando se aplica un forceps alto, hay o no hay distocia; porque por lo general lo que determina la falta de encajamiento es la deflexión de la cabeza fetal. No habiendo distocia ósea, la falta de encajamiento es secundaria a vicio de flexión. Cuáles serían en este caso los puntos básicos de indicación del forceps.

Dr. RAMIREZ.-En estos casos sí hay distocia, aunque no haya desproporción cefalo-pélvica. El doctor Rafael Peralta habla de distocias de encajamiento de causas secundarias y en estos casos sería de pensar que la distocia habría de resolverse con una mayor fuerza de las contracciones uterinas, pero sin embargo no se indican los ocitócicos. Es entonces cuando se aplica el forceps alto y se encaja la presentación, pero la reducción de la deflexión es a veces imposible. A este respecto no pueden darse reglas precisas de indicaciones y técnica y ante esta situación debe seguirse teniendo como condición para la aplicación del forceps, el encajamiento de la presentación. Es cierto que a veces se puede prescindir y se prescinde de esta condición, pero esto es ya un caso de conciencia del especialista obstetra.

Dr. GUILLERMO NAVAS.--Viene a cuento ahora el dilema que se tiene al escoger entre la aplicación de un forceps alto y la utilización de la expresión abdominal de Kristeller. Por la manera como frecuentemente se realiza esta última, de preferencia por personas de gran fuerza física que descargan el peso de su cuerpo y el poder de sus músculos sobre el útero grávido, considero que la expresión abdominal es salvaje y cruel y mucho más peligrosa para la madre y el feto que el forceps alto. 
Dr. CUBILLOS.-Está claro que el forceps alto puede ser eutócico o distócico y estas condiciones establecen lo bueno o malo de la conducta. En cuanto a la maniobra de Kristeller, ésta debe realizarse suavemente porque su finalidad se modifica cuando se hace con violencia.

Dr. SILVA.-El Kristeller es maniobra de comadronas. En su lugar debe utilizarse el forceps cuando se llenan las condiciones para su uso. Las maniobras de expresión deben desaparecer de la práctica obstétrica para ceder el campo a más frecuentes y oportunas aplicaciones del forceps.

Dr. OFMAN.-Al hablar de forceps alto no debería decirse aplicación sino intento de aplicación con lo que se daría a entender una maniobra sin esfuerzo ni insistencia para la extracción.

Dr. PACHON.--Muchas veces la falta de encajamiento está determinada por distocia de los anexos fetales, del tipo de las bravedades del cordón, que determinan sufrimiento fetal. Es lógico que este sufrimiento fetal se acentúe al encajar y descender la presentación con el forceps con el consiguiente atirantamiento funicular y entonces la conducta de elección sería la cesárea.

Dr. RAMIREZ.-La determinación de la conducta es cuestión de criterio del obstetra.

Dr. FERNANDEZ.-Debe tenerse también en cuenta la longitud del forceps empleado; en nuestro medio se utiliza casi siempre el de Simpson, que mide $32 \mathrm{cms}$. ( 15,6 y 11$)$ y que es corto para las tomas altas. Por otra parte, la curva pélvica del Simpson no se acomoda bien con la pelvis materna en esta clase de aplicaciones. Por estas razones, sería de preferir el forceps de Kielland, por ser más largo, de curva pélvica menos acentuada y que fue principalmente ideado para las variedades transversas y posteriores de vértice.

Dr. RAMIREZ.--En mi experiencia he podido comprobar que hay menos dificultad con el forceps de Simpson. El forceps de Kielland se utilizaba mucho cuando la operación cesárea se consideraba y era casi mortal. En los servicios de maternidad del Hospital de San Juan de Dios se hizo una tesis de grado, la del doctor Mejía Vieira, acerca del uso del forceps de Kielland y en ella se dedujo que los resultados son malos para los niños y a veces también para las madres.

Dr. FERNANDEZ.-En los Estados Unidos poco se usa el forceps alto y el Kielland se utiliza como rotador de variedades posteriores y transversas. En hospitales de ese país lo vi aplicar frecuentemente con buenos resultados.

Dr. RAMIREZ.-EI Kielland se utilizaba para tomas altas en transversa y para este uso, lo mismo que todos los demás modelos, está relegado. 